\title{
(5)
}

AL-DZIKRA

Jurnal Studi Ilmu Al-Qur'an Dan Al-Hadits

http://ejournal.radenintan.ac.id/index.php/al-dzikra

Volume 13, No. 1, Juni Tahun 2019, Halaman 55 - 70

DOI://dx.doi.org/10.24042/al-dzikra.v13i1.390o

\section{TAFSIR KENABIAN MIRZA GHULAM AHMAD}

\begin{tabular}{c}
\hline Supardi \\
STID Al-Biruni Cirebon \\
supardi.babakan@gmail.com \\
\hline
\end{tabular}

\section{Abstrak}

Artikel ini fokus pada kajian penafsiran tentang kenabian pendiri Ahmadiyah yaitu Mirza Ghulam Ahmad. Tujuan dari studi ini adalah untuk menganalisa proses penafsiran yang dilakukan oleh Mirza Ghulam Ahmad berikut pokok-pokok pemikirannya yang dianggap keluar dari Islam mainstream. Untuk mencapai tujuan-tujuan ini, penulis menggunakan pendekatan kualitatif agar dapat menyajikan data secara lebih detail dan mendalam, sehingga diperoleh hasil bahwa proses penafsiran Mirza Ghulam Ahmad dipengaruhi oleh factor sosialpolitik yang berkembang di masanya. Penafsirannya tentang konsep kenabian sangat berseberangan secara diametral terhadap teologi ortodok.

Kata kunci: Proses, Penafsiran, Konflik Sosial

\section{A. Pendahuluan}

Ahmadiyah sebagai gerakan sempalan bukanlah fenomena baru di dunia gerakan Islam. Justru, sejarah pergerakan Islam sendiri menyuguhkan ragam penyempalan dan sesekali memunculkan sikap saling menyempalkan. Setidaknya, ini diakui oleh Martin Van Bruinessen bahwa secara sosiologis, 
gerakan sempalan adalah konsekuensi dari dominasi sebuah paham atau aliran yang diistilahkan dengan ortodoksi atau mainstream.

Lebih lanjut, ia mengatakan bahwa fenomena ortodoksi dan sempalan pada ranah sosiologis tidak bersifat mutlak dan abadi melainkan relatif dan dinamis. Hal ini dibuktikan oleh sejarah pergumulan paham keagamaan di dunia Islam. Misalnya, paham Sunni pernah menjadi sempalan pada masa pemerintahan Abbasyiah yang menganut paham Muktazilah. Atau kehadiran al Irsyad dan Muhammadiyah yang menantang paham ortodoksi tradisional yang dianut mayoritas ulama Indonesia. ${ }^{1}$

Fenomena gerakan sempalan menjadi pusat perhatian para sosiolog. Sebut saja misalnya, Max Webber dengan teori Kepemimpinan Kharismatik yang dimunculkan dari penelitiannya terhadap peranan sekte-sekte protestan dalam proses kelahiran semangat kapitalisme. Begitu juga, Troeltsch meneliti fenomena sempalan di Eropa abad pertengahan dengan membedakan dua wadah umat beragama yang saling bertentangan yaitu tipe gereja dan tipe sekte. Tesisnya mengatakan bahwa lahirnya sempalan pertama-tama muncul di kalangan kelas bawah kemudian menyebar ke kelas-kelas berikutnya.

Penelitian berikutnya dilakukan oleh Richard Niebuhr mengambil setting sosial di Amerika Serikat yang melahirkan teori denominasi akibat protes-protes sosial terhadap stagnansi struktur organisasi keagamaan. Peneliti lain, Milton Yinger berusaha mengamati pola kecenderungan sekte-sekte di Amerika bahwa sekte yang lahir dari protes sosial cenderung stagnan pada sikap kesektean, sedangkan sekte yang menitikberatkan problem moralitas cenderung melakukan denominasi.

Lebih lanjut, Bryan Wilson mengembangkan hasil-hasil penelitian sebelumnya dengan menyusun tipologi sekte berdasarkan sikap terhadap dunia sekitar. Ia merumuskan tujuh tipe ideal sekte, antara lain, tipe conversionist (perbaikan moral individu), revolusioner (perubahan sosial secara radikal), introversionis (keselamatan anggota), gnostic (metode khusus

${ }^{1}$ Bruinessen, Gerakan Sempalan di Kalangan Umat Islam Indonesia: Latar Belakang Sosial-Budaya. Jurnal Ulumul Qur'an,1992, hlm.16-19 
mencapai keselamatan), thaumaturgical (pengobatan dan ilmu gaib), reformis (harmonisasi agama dan sosial), dan utopian dalam bentuk keteladanan sosial. ${ }^{2}$

\section{B. Mirza Ghulam Ahmad dan Ahmadiyah: Dulu Hingga Kini}

India dulu dikenal sebagai satu wilayah yang meliputi beberapa Negara yang kita kenal dewasa ini, yakni India, Pakistan, dan Bangladesh. Wilayah ini dipisahkan oleh "benteng alam" pegunungan Himalaya di sebelah utara dan pegunungan Hindu Kusy di sebelah Barat laut. Sebelum Islam masuk dan menyebar di India, di sana telah lahir agama Hindu, Buddha, Jain dan Sikh. ${ }^{3}$

Awal abad ke-8 Islam mulai masuk ke India melalui jalur politik. Saat itu, khalifah al Walid bin Abdul Malik (388-421 H) dari dinasti Bani Umayyah melakukan agresi militer yang dipimpin oleh Muhammad bin Qasim ke daerah Sind mulai tahun $712 \mathrm{M}^{4}$ Sejak saat itu, kekuatan politik Islam melembaga dalam bentuk dinasti yang dimulai dengan dinasti Ghazni yang berpusat di Afganistan pada tahun 961 M yang dilanjutkan oleh dinasti Ghuri.

Di akhir kekuasaan dinasti Ghuri, muncul kesultanan Delhi yang didirikan oleh Kutbuddin Aibak tahun 1206-1290. ${ }^{5}$ Berikutnya, kekuasaan politik Islam di India silih berganti sampai berdirinya dinasti Moghul yang berkuasa sejak 1526-1857. Kejatuhan kekuasaan dinasti Mughal di India sekurang-kurangnya disebabkan oleh empat factor utama yaitu krisis kepemimpinan, kebangkitan politik Hindu dibawah kepemimpinan Maratha, ${ }^{6}$

${ }^{2}$ Bruinessen, Gerakan Sempalan di Kalangan Umat Islam Indonesia: Latar Belakang Sosial-Budaya. Jurnal Ulumul Qur'an,1992. hlm. 24

${ }^{3}$ Sa'id an Nadwi, M. F., Ahmadiyah Sekte atau Agama Baru, (Tuban: Pustaka Langitan, 2006)

${ }^{4}$ Esposito, J. Islam in Asia Religion, Politic and Society, (New York: Oxford University Press, 1987), hlm. 53

5 Mulia, T. India: Sejarah Politik dan Kebangsaan. (Jakarta: Balai Pustaka, 1952), hlm. 40

${ }^{6}$ Sayeed, K. B. Pakistan the Formative Phase 1857-1948. (London: Oxford University Press, 2005), hlm. 3 
kolonialisasi Inggris yang semakin menguat, ${ }^{7}$ Jatuhnya dinasti Mughal menandai melemahnya kekuatan politik Islam pada kancah internasional. Sebelumnya, dinasti Safawi luluh lantak pada awal abad ke-18 $\mathrm{M}^{8}$ kemudian diikuti kemerosotan dinasti Turki Utsmani sampai runtuh pada tahun 1924 setelah berkuasa selama enam abad lamanya, ${ }^{9}$ Setelah dinasti-dinasti lama berguguran satu demi satu, dunia Islam memasuki masa kemunduran dalam berbagai bidang. Tidak hanya bidang politik melainkan juga bidang ekonomi, sosial, budaya, dan intelektual. ${ }^{10}$

Kemunduran Islam di sana-sini menyadarkan umat Islam untuk mengembalikan kejayaan yang pernah mereka nikmati. Di akhir abad ke-19 mulai bermunculan para tokoh yang mencoba menggelorakan kembali semangat Islam karena mereka yakin bahwa kembali kepada Islam satu-satunya cara merengkuh kejayaan masa silam. Dari Afganistan, muncul Sayyed Jamaluddin al Afghani (1839-1897) yang mengusung panislamisme yang kemudian memengaruhi Muhammad Abduh (1849-1905) dan Rasyid Ridlo (1865-1935) di Mesir untuk membangkitkan semangat nasionalisme Mesir.

Sementara itu, di India muncul Sir Sayid Ahmad Khan (1817-1898) dengan idenya tentang saintifikasi Islam, ${ }^{11}$ (Nasution, 2002) dan Sir Muhammad Iqbal (1873-1938) yang lekat dengan rekonstruksi pemikiran Islam melalui karyanya The Reconstruction of Religion Thought in Islam pada tahun $1930^{12}$, tokoh berikutnya yang muncul dari dataran Asia Selatan, tepatnya dari Pakistan, adalah Muhammad Ali Jinnah (18761948) yang mengusung ide nasionalisme Islam sebagai reaksi

\footnotetext{
${ }^{7}$ Burhanudin, A. Jihad Tanpa Kekerasan. Yogyakarta: LKiS, 2005), hlm. 29

${ }^{8}$ Yatim, B. Sejarah Peradaban Islam: Dirasah Islamiyah II. (Jakarta: PT. Grafindo Persada, 2008), hlm. 174

${ }^{9}$ Hitti, P. K. Hostory of the Arab. London: The Mac Millan Press, 1974), hlm. 710

10 Suyoto. Al-Islam 2, (Malang: Pusat Dokumentasi dan Kajian al Islam, 1992), hlm. 202

11 Nasution, H. Islam Ditinjau dari Berbagai Aspeknya. (Jakarta: UI Press, 2002), hlm. 106

12 Iqbal, M. The Reconstruction of Religious Thought is Islam. (Islamabad: Dodo Press, 2009)
} 
terhadap ide nasionalisme Hindu yang diusung dalam Partai Kongres. ${ }^{13}$

Ide-ide pembaharuan di India lahir dari situasi kekacauan sosial-politik dan keagamaan akibat kapitalisme industri Inggris yang menguras kekayaan India dan berangsur-angsur menjadikan India Negara amat miskin. Problem ekonomi, kemiskinan dan kelaparan serta sikap konservatif umat Islam menjadi gerbang yang terbuka lebar bagi missionaris dari kalangan Kristen dan Hindu pimpinan Arya Samaj. Hal ini menyebabkan migrasi ke agama di luar Islam tak dapat dibendung lagi. ${ }^{14}$

Faktor-faktor ini sekaligus memberikan inspirasi sebuah gerakan yang diinisiasi oleh Mirza Ghulam Ahmad (1835-1905). Menurut Gibb, gerakan ini menjadi satu-sat unya sekte yang lahir dengan nuansa liberal dan cinta damai yang bertujuan untuk menarik perhatian masyarakat yang terlanjur jenuh dengan pola pemahaman Islam klasik. ${ }^{15}$

Pertama-pertama, gerakan ini lahir di Qadian, sebuah kota kecil yang terletak di distrik Gurdaspur, Punjab, India. ${ }^{16}$ Nama Qadian bermula dari keberadaan Mirza Hadi Beg yang diangkat oleh pemerintah sebagai Qadli (hakim) untuk daerah sekitarnya. Teritorial hukum ini disebut dengan istilah Islampur Qadli. Lambat laun, kata Islampur dihilangkan dan kata Qadli berubah menjadi Qadian. ${ }^{17}$

Kepemilikan daerah oleh keluarga Mirza Hadi Beg memasuki beberapa fase sejarah. Pada masa pemerintahan Sikh, kawasan ini direbut sehingga memaksa keluarga Hadi Beg mengungsi ke daerah kekuasaan kesultanan Kapultara. Setelah Maharaja Ranjit Singh berkuasa, sebagian wilayah ini dikembalikan kepada ayah Ghulam Ahmad yang saat itu menjadi

13 Nasution, H. Islam Ditinjau dari Berbagai Aspeknya, (Jakarta: UI Press, 2002), hlm. 108

14 Ahmad, M. G. Our Teaching, (United Kingdom: Islam International Publication Limited, 2016), hlm. 27

${ }^{15}$ Gibb, H. A. Aliran-Aliran Modern dalam Islam, (Jakarta: PT. Raja Grafindo, 1995), hlm. 104

${ }^{16}$ Zurkarnain, I. Gerakan Ahmadiyah di Indonesia, (Yogyakarta: LKiS, 2015), hlm. 65-66

${ }^{17}$ Adamson, I. Mirza Ghulam Ahmad dari Qadian, (United Kingdom: Islam Internasional Publication Limited, 1989), hlm. 19 
tentara kerajaan. Namun, setelah Sikh dikalahkan oleh Inggris, semua kekayaan dan daerah kekuasaan keluarga Ghulam Murtadla, ayah Ghulam Ahmad, diambil alih. Hanya satu distrik yang tidak dikuasai, yaitu distrik Qadian. ${ }^{18}$

Di bawah kekuasaan kolonial Inggris, Mirza Ghulam Ahmad lahir dan memulai tahapan perkembangan intelektualnya. Ia berkonsentrasi pada persoalan perbandingan agama-agama; khususnya agama Kristen dan Hindu Brahma Samaj, melalui tulisan-tulisan di beberapa media massa. Akhirnya, pada tahun 1880, ia menerbitkan sebuah buku berjudul Barahin Ahmadiyah yang memuat argumentasi-argumentasi keunggulan Islam dari pada Kristen dan Hindu. ${ }^{19}$

Tiga tahun setelahnya, 1883, Mirza Ghulam Ahmad begitu popular di kalangan umat Islam India. Banyak yang ingin mengikuti dan mengikat janji setia sebagai murid. Akan tetapi, hal ini baru terjadi pada tanggal 23 Maret 1889, sebanyak 40 orang melakukan bai'at di rumah Mia Ahmad Jean, Ludiana India (Ahmadiyah Indonesia, 1994). Pembai'atan ini dinyatakan sebagai awal mula berdirinya al Jama'ah al Islamiyyah Ahmadiyyah. ${ }^{20}$

Sejak diresmikan, gerakan ini berkembang pesat dan menyebar ke berbagai daerah di India. Kondisi internal gerakan ini masih stabil meski sang pendiri telah wafat pada tahun 1905 dan digantikan oleh Maulvi Hakim Nuruddin (1841-1914) sebagai khalifah I dari tahun 1908 sampai $1914 .^{21}$ Untuk menunjang perjuangan dan gerakan, dibentuklah badan organisasi pusat (Anjuman) untuk menangani hal-hal teknis dan administrasi bernama Sadr Anjuman Ahmadiyah. Maulvi Nuruddin menjadi

18 Ahmad, M. B. Sirat Masih Mau'ud a.s. (United Kingdom: Islam International Publication Limited, 2012), hlm. 2

${ }^{19}$ (Burhanudin, 2005), hlm. 35

${ }^{20}$ Sa'id an Nadwi, M. F. Ahmadiyah Sekte atau Agama Baru. (Tuban: Pustaka Langitan, 2006), hlm. 134

${ }^{21}$ Ahmad, S. H. Hakeem Noor-Ud-Deen (Khalifatul Masih I): The Way of The Righteous. (United Kingdom: Islam International Publications Limited, 2003) 
Khalifah sekaligus ketua organisasi pusat ini dan Muhammad Ali sebagai sekretaris. ${ }^{22}$

\section{Tahapan Penafsiran Mirza Ghulam Ahmad}

a. Membuka kembali pintu wahyu

Kata wahyu beserta derivasinya dalam al-Qur'an disebutkan sebanyak 78 kali dalam 33 surat, yaitu dalam bentuk kata benda sebanyak 6 kali dan dalam bentuk kata kerja sebanyak 72 kali. $^{23}$ Menurut para ahli tafsir, term ini mencakup tujuh makna, yakni al Irsal (pengangkatan sebagai Nabi dan Rasul), al Isyarah (mengisyaratkan), al Ilham (petunjuk Allah yang muncul dalam hati), al Qaul (firman Allah), I'lam fi al Manam (informasi dalam mimpi), dan I'lam bi al Waswasah (bisikan). ${ }^{24}$

Diskursus wahyu di kalangan intelektual Islam di masa skolastik, ada pendikotomian antara wahyu dan ilham. Di mana wahyu bersifat tertutup dan temporal hanya berlaku bagi Nabi di masa hidupnya sedangkan ilham bersifat terbuka dan tak berbatas waktu berlaku bagi selain nabi. ${ }^{25}$

Hal menarik dari penafsiran Mirza Ghulam Ahmad pada persoalan wahyu adalah usahanya untuk membuka kembali pintu wahyu yang selama ini tertutup rapat. Pandangannya terekam sebagai berikut ${ }^{26}$ :

Janganlah hendaknya kamu mengira bahwa wahyu ilahi itu tidak mungkin ada lagi di waktu yang akan datang dan wahyu itu hanya berlaku pada masa yang telah lampau kala (syariat berakhir pada al-Qur'an, tetapi wahyu tidak berakhir. Karena agama yang hidup ditandai oleh kelangsungan wahyu, agama yang silsilah wahyunya tidak

${ }^{22}$ Iskandar, N. R. Hasil Studi Banding Ahmadiyah. (Jakarta: Darul Kutubil Islamiyah, 2005), hlm. 9-10

23 Abd al Baqi, M. F. al Mu'jam al Mufahras Li Alfazh al-Qur'an al Karim. Beirut: Dar al Fikr, 1981)

${ }^{24}$ Ibn al Jauzi,. Nuzhat al 'Uyun an Nawazir fi 'Ilm al Wujuh wa an Nazhair, (Beirut: Muassat ar Risalah, 1987), hlm. 192.

${ }_{25}$ Abu Zaid, N. H. Tekstualitas al-Qur'an: Kritik Terhadap Ulumul Qur'an, (Yogyakarta: LKiS, 2001), hlm. 42

26 Ahmad, M. G. Tadzkirah: dari Wahyu, Mimpi, dan Kasyaf yang Diterima, (Islamabad: Nertja Press, 2014), hlm. 31 
berkelanjutan adalah mati dan Tuhan tidak bersamanya) jangan mengira Roh-Kudus tidak dapat turun di masa sekarang dan hal itu tidak hanya berlaku di masa dahulu.

Jika kita cermati dalam Tadzkirah -menurut penulis lebih mirip seperti manaqib di kalangan tarekat- akan didapati istilahistilah yang berkaitan dengan pengalaman transenden ini. Ghulam Ahmad menggunakan tiga kata kunci dalam kitab itu, yakni ru'ya, kasyaf, dan wahyu. Dua kata pertama seringkali digunakan oleh Mirza Ghulam Ahmad untuk memberitahukan inspirasi yang diperolehnya melalui mimpi. Namun, sepertinya, ia membedakan antara ru'ya dan kasyaf. Ia mengatakan "dalam sebuah ru'ya yang sebenarnya sebuah kasyaf yang jelas. Ru'ya identik dengan mimpi sedangkan kasyaf ia alami dalam keadaan terjaga "Aku teringat dengan jelas sebuah kasyaf berikut ini: setelah shalat maghrib ketika dalam keadaan terjaga sepenuhnya, aku merasakan kebebasan di anggota-anggota tubuhku..." tegasnya pada tahun 1875. Sedangkan kata wahyu dalam kisahnya "dalam keadaan setengah tidur aku menerima wahyu..."27

Maulana Muhammad Ali mencoba mengurai pemikiran Mirza Ghulam Ahmad di atas bahwa wahyu diklasifikasikan menjadi lima macam sebagaimana terekam dalam al-Qur'an yaitu wahyu kepada benda mati, binatang, malaikat, manusia pada umumnya, dan kepada Nabi. ${ }^{28}$

Ia menegaskan bahwa ada tiga pola komunikasi antara Tuhan dan hamba-Nya yakni (1) melalui wahyu yaitu sabda yang diilhamkan ke dalam kalbu para nabi dan orang-orang tulus, (2) dari balik tabir yang termanifestasikan dalam tiga bentuk yakni mubasyarah (mimpi yang baik), kasyaf (melihat dengan mata rohani), dan ilham (mendengar dengan telinga rohani), dan (3) mengutus malaikat jibril. ${ }^{29}$

Mengenai persoalan temporalitas wahyu yang dibuka kembali oleh Mirza Ghulam Ahmad, ada sedikit petunjuk dari buku tiga masalah penting, bahwa wahyu syariat tidak mungkin

27 Khan, M. Z. Tadhkirah, (London: Saffron Books, 1908), hlm. 19

28 Ali, M. M. Qur'an Suci, Teks, Arab, (Jakarta: Darul Kutubil Islamiyah, 1979), hlm. 695

29 Ali, M. M. Qur'an Suci, Teks, Arab, (Jakarta: Darul Kutubil Islamiyah, 1979), hlm. 168-169 
turun lagi sesudah al-Qur'an sebab syariat al-Qur'an telah sempurna dan berlaku hingga akhir dunia. Sedangkan wahyu tanpa syariat, mungkin saja turun sewaktu-waktu. ${ }^{30}$

Pada persoalan ini relatif tidak ada perbedaan tajam di antara Ahmadiyah Qadian dan Lahore. Perbedaan itu justru ada antara Ahmadiyah dan non-Ahmadi. Pengikut Ahmadiyah menggunakan satu istilah wahyu untuk menggambarkan seluruh interaksi tuhan dan manusia. Sedangkan non-Ahmadi memberikan distingsi penisbatan wahyu bagi nabi dan ilham bagi selain nabi.

\section{b. Daur Ulang Konsep Kenabian}

Sebelumnya kita telah mengutip penafsiran Mirza Ghulam Ahmad tentang wahyu yang dikaitkan dengan eksistensi sebuah agama. Setidaknya, kutipan di atas menjadi pijakan pemikiran berikutnya tentang objek penerima wahyu. Logikanya, jika wahyu masih berlangsung maka harus ada sosok penerima untuk menjalankan misi wahyu tersebut.

Sebelum mengurai konsep kenabian di kalangan Ahmadiyah perlu kiranya kita melihat fase beberapa istilah yang digunakan oleh Mirza Ghulam Ahmad. Dalam buku Barahin Ahmadiyah yang di terbitkan tahun 1880 berisi seputar kekeramatan dan kewaliannya. Kemudian, lima tahun berikutnya, ia menyatakan diri sebagai seorang pembaharu (mujaddid) yang akan memberikan penyegaran terhadap konstruksi Islam saat itu. Ia menyatakan "bukan seorang nabi akan tetapi ditunjuk oleh Allah menjadi pembaharu yang bertugas memperbaharui agama yang dibawa oleh Nabi Muhammad", lanjutnya "bukan seorang nabi, akan tetapi seorang muhaddits. ${ }^{31}$ Tiga tahun berikutnya, tepatnya tahun 1888, ia menyatakan bahwa mendapat informasi berupa wahyu ilahi yang isinya menerima bai'at dari para pengikutnya dan membuat wadah bagi misi dan cita-cita sucinya untuk menyebarkan Islam ke seluruh penjuru dunia. ${ }^{32}$ Baru setelah menyatakan mendapat wahyu ilahi, Mirza Ghulam Ahmad

30 Cheema H.A., H. A. Tiga Masalah Penting, (Bogor: Jemaat Ahmadiyah Indonesia, 1996), hlm.13

${ }^{31}$ Dzahir, I. I., Ahmadiyah Qadianiyah: Sebuah Kajian Analitis, (Jakarta: ttp, 2008), hlm. 100-114

${ }^{32}$ Zurkarnain, I. Gerakan Ahmadiyah di Indonesia. (Yogyakarta: LKiS, 2015), hlm. 84 
menyematkan istilah "al Mahdi al Ma'hud (Imam Mahdi yang dijanjikan)" dan "al Masih al Mau'ud (Nabi Isa yang akan datang)" secara berturut-turut pada tahun 1891. Ia tidak hanya menggunakan istilah-istilah yang disakralkan oleh umat Islam melainkan juga mengadopsi istilah agama Hindu di mana ia memproklamirkan diri sebagai representasi "Krisna" pada tahun $1904 .{ }^{33}$

Kegaduhan intelektual muncul disebabkan oleh penyematan tern "nabi" yang digunakan oleh Mirza Ghulam Ahmad. Sebuah istilah yang sakral dan hampir tidak pernah terjadi pemaknaan ulang. Kata ini mengandung sensitivitas tinggi di kalangan umat Islam yang "terlanjur" percaya bahwa kata ini sudah tak layak digunakan pasca wafatnya Nabi Muhammad.

Meskipun demikian, bukan berarti term ini luput dari diskusi ilmiah di kalangan intelektual muslim klasik. Perbincangan mengenai istilah ini seputar katerkaitan antara "nabi" dan "rasul". 34 Ada yang menyamakan antara keduanya sehingga dapat dipergunakan secara bergantian dan ada pula yang membuat distingsi antar keduanya. ${ }^{35}$

Kata "nabi" dalam al-Qur'an terulang sebanyak 75 kali sedangkan kata "naba" terulang sebanyak 29 kali. Secara etimologis, kata ini berasal dari bahasa arab, naba', berarti warta (news), berita (tidings), informasi (information), laporan (report). ${ }^{36}$ Ragib al Isfahani menambahkan bahwa informasi yang disampaikan bukan informasi biasa melainkan informasi yang valid dan tidak mungkin salah. ${ }^{37}$

Berbeda dari pemaknaan "nabi" secara etimologi, pemaknaan "nabi" cukup beragam secara terminologis. Nabi adalah seseorang yang menerima wahyu ilahi melalui malaikat, ilham, maupun mimpi yang benar yang berfungsi sebagai

${ }^{33}$ (Burhanudin, 2005), hlm. 54

${ }^{34}$ Ash Shobuni, M. A., an Nubuwwah wa al Anbiya', (Beirut: A'lam al Kutub, 1985), hlm. 14

${ }^{35}$ Abdullah, T., Ensiklopedi Tematis Dunia Islam, (Jakarta: PT. Ichtiar Van Houve, 2000), hlm. 14

${ }^{36}$ Ibn Manzhur, A., Lisan al 'Arab, (Beirut: Dar Sadr, 1883), hlm. 561

${ }^{37}$ Raharjo, M. D., Ensiklopedi al-Qur'an, (Jakarta: Paramadina, 1997), hlm. 303 
mubasyir dan mundzir. ${ }^{38}$ Sedangkan, Ciryl Glasse mendefinisikan "nabi" sebagai seseorang yang menjalankan tugas kenabiannya dalam bingkai wahyu yang telah ada sebelumnya ${ }^{39}$ atau, meminjam bahasa Aceng Abdul Kodir, bahwa nabi menyampaikan wahyu melalui keteladanan pribadi atas bimbingan wahyu. ${ }^{40}$

Berangkat dari makna semantic "nabi" dan filsafat kewahyuan yang dianut Ahmadiyah, mereka mencoba merekonstruksi ulang pemaknaan "nabi". Menurut mereka "nabi" dapat diklasifikasikan ke dalam dua kategori yakni nabi tasyri' atau Nabi Shabib asy Syariah atau Nabi Mustaqil yang direpresentasikan oleh Musa dan Muhammad dan nabi ghairu tasyri' seperti Ismail dan Harun. Selanjutnya, jenis kedua ini diklasifikasikan menjadi dua, yakni nabi mustaqil ghairu tasyri' adalah seorang nabi yang tidak terikat dengan syariat nabi sebelumnya seperti Luth, Ismail, Harun, Daud, dan Sulaiman, dan nabi zhilli ghairu tasyri' nabi yang terikat dengan nabi yang membawa syariat sebelumnya (Ahmadiyah Indonesia, Mengenai kenabian, 1999) karena hasil ketaatan menjalankan syariat nabi sebelumnya. Menurut Ahmadiyah Qadian di sinilah posisi Mirza Ghulam Ahmad yaitu sebagai nabi zhilli ghairu tasyri'.

Sebagai perbandingannya, konsep kenabian yang dianut oleh Ahmadiyah Lahore terbagi menjadi dua kategori yakni nabi haqiqi di mana seseorang menjadi nabi sebab ditunjuk langung oleh Allah dan membawa syariat dan yang kedua adalah nabi lughawi di mana ia hanya manusia biasa tetapi memiliki banyak kemiripan dengan nabi yang lain, khususnya pada persoalan penerimaan wahyu dan dimensi kemahdian. ${ }^{41}$

Mereka meyakini bahwa kata "nabi" yang dipakai oleh Mirza Ghulam Ahmad untuk menunjukkan dimensi kenabian melalui pengalaman spiritual yang telah ia jalani. Ia mengenalkan

${ }^{38}$ Ibn Manzhur, A., Lisan al 'Arab, (Beirut: Dar Sadr, 1883)

39 Glasse, C., The Concise Encyplopedia of Islam, (San Francisco: Harper \& Row Publisher Inc, 1989), hlm. 342

${ }^{40}$ Abdul Hadits dan Dominasi Wacana Islam Autentik pada Tiga Abad Pertama Hijriyah. Wawasan: Jurnal Ilmiah Agama dan Sosial Budaya, hlm. 212.

${ }^{41}$ Djajasugito, F. A., Studi Islam: Peta Penyebaran Ahmadiyah Lahore di Dunia, (Jakarta: Darul Kutubil Islamiyah, 2006), hlm. 7-8 
konsep fana fi ar rasul yaitu sebuah proses peleburan diri dalam diri rasulullah Muhammad dengan melakukan kepatuhan sebagai ummati sehingga eksistensinya lenyap bahkan berganti wujud menjadi bayangan (zhilli) Muhammad. ${ }^{42}$ Ia mengatakan $^{43}$ :

Aku Adam, aku Set, aku Nuh, aku Ibrahim, aku Ishaq, aku Ismail, aku Ya'qub, aku Yusuf, aku Musa, aku Daud, aku Isa dan aku adalah penjelmaan sempurna dari Nabi Muhammad saw.

\section{Kesimpulan}

Ahmadiyah merepresentasikan diri sebagai gerakan pembaharuan dalam Islam. Ide besar yang ingin dikonstruksikan adalah kebangkitan Islam pasca keruntuhannya dengan alur pemikiran yang relatif berbeda dan agak "nyentrik". Namun, pada satu titik, ia sama seperti nuansa pembaharuan akhir abad XIX-XX yang mengedepankan pada pembacaan Islam yang lebih rasional dan kontekstual.

Konstruksi pemikiran rasional ini akhirnya mengantarkan Mirza Ghulam Ahmad beserta para pengikutnya kepada kesimpulan-kesimpulan yang jauh berbeda dari umat Islam mainstream. Ia mencoba membuka kembali wacana jalur transmisi wahyu yang dianggapnya tidaklah berhenti sama sekali. Hal yang sama juga terjadi pada persoalan kenabian yang terbuka lebar bagi umat Muhammad. Nabi, baginya, sebuah tingkatan spiritual yang mampu diraih jika memenuhi syarat-syarat tertentu. Pemikiran terakhirnya adalah tentang Mahdiisme atau Messianisme. Berbeda dari mayoritas umat Islam bahkan seluruh penganut agama-agama dunia. Mirza Ghulam Ahmad mengaku sebagai Imam Mahdi bagi umat Islam, Isa bagi Kristen, dan Krisna kedua bagi umat Hindu.

42 Ahmad, M. G., Tadzkirah: dari Wahyu, Mimpi, dan Kasyaf yang Diterima, (Islamabad: Nertja Press, 2014), hlm. 12

${ }^{43}$ Batubara, F. K., Kritik Teologi Kenabian Mirza Ghulam Ahmad, (Sumatera Utara: Pascasarjana UIN Sumatera Utara, 2017) 


\section{DAFTAR PUSTAKA}

Abd al Baqi, M. F. al Mu'jam al Mufahras Li Alfazh al Qur'an al Karim. Beirut: Dar al Fikr, 1981

Abdul Kodir, A. Sejarah Bid'ah: Ashhab al Hadits dan Dominasi Wacana Islam Autentik pada Tiga Abad Pertama Hijriyah. Wawasan: Jurnal Ilmiah Agama dan Sosial Budaya, 2016

Abdullah, T. Ensiklopedi Tematis Dunia Islam. Jakarta: : PT. Ichtiar Van Houve, 2000

Abu Zaid, N. H. Tekstualitas al Qur'an: Kritik Terhadap Ulumul Qur'an .Yogyakarta: LKiS, 2001

Adamson, I. Mirza Ghulam Ahmad dari Qadian. United Kingdon : Islam Internasional Publication Limited, 1989

Ahmad, M. B. Sirat Masih Mau'ud a.s. United Kingdom: Islam International Publication Limited, 2012

Ahmad, M. G. The British Government and Jihad. United Kingdom: Islam International Publications Ltd, 2006

, Tadzkirah: dari Wahyu, Mimpi, dan Kasyaf yang Diterima.Islamabad: Nertja Press, 2014

Our Teaching. United Kingdom: Islam International Publication Limited, 2016 , Al-Washiyyat. Yogyakarta: PB GAI, 1994 , Yesus di India: Kisah Kelepasan Yesus dari kematian di Atas Kayu Salib dan Perjalanannya ke India. United Kingdom: Islam International Publication Limited, 1995

Ahmad, S. H. Hakeem Noor-Ud-Deen (Khalifatul Masih I): The Way of The Righteous. United Kingdom: Islam International Publications Limited, 2003

Ahmad, S. M. Welcome to Ahmadiyyat: The True Islam. United Kingdom: Islam International Publication Limited, 2007

Ahmadiyah Indonesia, J. Mengenai kenabian. Artikel Jemaat Ahmadiyah Indonesia, 1999

------------, Suvenir Peringatan Seabad Gerhana Bulan dan Gerhana Ramadhan 1894-1994. Parung: JAI, 1994 
Ali, M. M. Qur'an Suci, Teks, Arab. Jakarta: Darul Kutubil Islamiyah, 1979

Ali, M. M. Gerakan Ahmadiyah. Jakarta: Darul Kutubil Islamiyah, 2002

Ali, M. R. Kebenaran Al-Masih Akhir Zaman. Jakarta: Neratja Press, 2017

As Siyali, J. a. Tarikh Daulah 'Abatirah al Mughul al Islamiyyah. Iskandariyah: Mansyaat al Ma'arif, 1968

Ash Shobuni, M. A. an Nubuwwah wa al Anbiya'. Beirut: Alam al Kutub, 1985

At Turmudzi. (tt.). Sunan at Turmudzi. Semarang: Thaha Putra.

Batubara, F. K. Kritik Teologi Kenabian Mirza Ghulam Ahmad.

Sumatera Utara: Pascasarjana UIN Sumatera Utara, 2017

Burhanudin, A. Jihad Tanpa Kekerasan. Yogyakarta: LKiS, 2005

Bruinessen, M. V. Gerakan Sempalan di Kalangan Umat Islam Indonesia: Latar Belakang Sosial-Budaya. Jurnal Ulumul Qur'an, 1992

Cheema H.A., H. A. Tiga Masalah Penting. Bogor: Jemaat Ahmadiyah Indonesia, 1996

Djajasugito, F. A. Studi Islam: Peta Penyebaran Ahmadiyah Lahore di Dunia. Jakarta: Darul Kutubil Islamiyah, 2006

Djojosugito, S. Hazrat Mirza Ghulam Ahmad Bukan Nabi Hakiki. Yogyakarta: PB GAI, 1984

Dzahir, I. I. Ahmadiyah Qadianiyah: Sebuah Kajian Analitis. Jakarta: ttp, 2008

Esposito, J. Islam in Asia Religion, Politic and Society. New York: Oxford University Press, 1987

Fadhillah, N. F. Towards Peaceful Islam: Jemaat Ahmadiyah Indonesia (JAI) as A New Social Movement. MASYARAKAT: Jurnal Sosiologi, 2017

Gibb, H. A. Aliran-Aliran Modern dalam Islam. Jakarta: PT. Raja Grafindo, 1995

Glasse, C. The Concise Encyplopedia of Islam. San Francisco: Harper \& Row Publisher Inc, 1989 
Hitti, P. K. Hostory of the Arab. London: The Mac Millan Press, 1974

Ibn al Jauzi, Nuzhat al 'Uyun an Nawazir fi 'Ilm al Wujuh wa an Nazhair. Beirut: Muassat ar Risalah, 1987

Ibn Manzhur, A. Lisan al 'Arab. Beirut: Dar Sadr, 1883

Iqbal, M. The Reconstruction of Religious Thought is Islam. Islamabad: Dodo Press, 2009

Iskandar, N. Mujaddid, Masih dan Mahdi. Jakarta: Darul Kutubil Islamiyah, 2009

Iskandar, N. R. Hasil Studi Banding Ahmadiyah. Jakarta: Darul Kut ubil Islamiyah, 2005

Kaiser, A. F. Yesus Wafat di Kashmir. Jakarta: Darul Kutubil Islamiyah, tt.

Khan, M. Z. Tadhkirah. London: Saffron Books, 1908

Madjid, N. Islam Agama Peradaban: Membangun Makna dan Relevansi Doktrin Islam dalam Sejarah. Jakarta: Yayasan Wakaf Paramadina, 1995

Manshur, H. Nubuwwah dalam Perspektif Ahmadiyah Qadian. Yogyakarta: UIN Sunan Kalijaga, 2005

Marvasti, A. B. Metodologi Kualitatif dalam Sosiologi. London: Sage Publication, 2004

Maulana, D. R. Ahmadiyah Lahore di Yogyakarta 1924-1930: Suatu pertumbuhan Awal di Pulau Jawa. Depok: Universitas Indonesia, 2010

Mukromin, N. Pemikiran Mirza Ghulam Ahmad Tentang Manusia. Yogyakarta: UIN Sunan Kalijaga, 2009

Mulia, T. India: Sejarah Politik dan Kebangsaan. Jakarta: Balai Pustaka, 1952

Nasution, H. Islam Ditinjau dari Berbagai Aspeknya. Jakarta: UI Press, 2002

Raharjo, M. D. Ensiklopedi al-Qur'an. Jakarta: Paramadina, 1997

RI, D. A. Ensiklopedia Islam Indonesia. Jakarta: Depag, 1988

Sa'id an Nadwi, M. F. Ahmadiyah Sekte atau Agama Baru. Tuban: Pustaka Langitan, 2006 
Sayeed, K. B. Pakistan the Formative Phase 1857-1948. London: Oxford University Press, 2005

Su'ud, A. Memahami Sejarah Bangsa-Bangsa Asia Selatan Sejak Jaman Purba Sampai Kedatangan Islam. Jakarta: Depdikbud, 1998

Suyoto. A1-Islam 2. Malang: Pusat Dokumentasi dan Kajian al Islam, 1992

Wahid, A. Prisma Pemikiran Gus Dur. Yogyakarta: LKiS, 1999

World Assembly, T. T.-U. Teladan Abadi Imam Mahdi. Jakarta: Penerbit al Huda, 1007

Yatim, B. Sejarah Peradaban Islam: Dirasah Islamiyah II. Jakarta: PT. Grafindo Persada, 2008

Zurkarnain, I. Gerakan Ahmadiyah di Indonesia. Yogyakarta: LKiS, 2015 